\title{
Transfer of Corynebacterium pyogenes (Glage) Eberson to the Genus Actinomyces as Actinomyces pyogenes (Glage) comb. nov'
}

\author{
C. A. REDDY, C. P. CORNELL, AND A. M. FRAGA \\ Department of Microbiology and Public Health, Michigan State University, East Lansing, Michigan 48824
}

\begin{abstract}
The physiology, metabolism, nutrition, and biochemical characteristics of Corynebacterium pyogenes (Glage) Eberson were studied in detail to determine the taxonomic status of this organism. $C$. pyogenes is a gram-positive, nonmotile, nonsporulating, short, rod-shaped bacterium which produces acid but not gas from a variety of carbohydrates. A number of amino acids were tested and did not appear to serve as sources of energy for growth. $C$. pyogenes is urease and catalase negative, does not reduce nitrates, and does not produce indole. Wide zones of $\beta$-hemolysis on blood agar, acid coagulation of litmus milk, and digestion of the clot are characteristic. Growth is comparable under aerobic and strictly anaerobic conditions. Metabolism is strictly fermentative. Glucose is fermented in $\mathrm{CO}_{2}$-containing media to succinate, acetate, formate, and lactate; no propionic acid is produced. In identical media without $\mathrm{CO}_{2}$, lactate is the major product, and only small amounts of acetate, succinate, and formate are produced. Hemin is stimulatory or required for growth. $\mathrm{CO}_{2} / \mathrm{HCO}_{3}{ }^{-}$and inositol seem to be obligatory growth factors. Certain peptides appear to relieve the requirement for inositol. All strains require riboflavin and nicotinic acid, and most require adenine and uracil for optimal growth. Characteristic cell wall sugar components are rhamnose and glucose, and the major diamino acid of peptidoglycan is lysine. Cells contain a type $b$ cytochrome. Based on these data, we propose that $C$. pyogenes be transferred to the genus Actinomyces as Actinomyces pyogenes (Glage) comb. nov.
\end{abstract}

Corynebacterium pyogenes (Glage) Eberson (34) is frequently isolated from a variety of pyogenic disease conditions in cattle, sheep, goats, pigs, and other domestic animals $(5,34)$ and from humans $(1,8,29,41)$. It has long been recognized that $C$. pyogenes bears little similarity to Corynebacterium diphtheriae (the type species) and related animal-pathogenic corynebacteria, such as Corynebacterium pseudotuberculosis and Corynebacterium kutscheri, and that $C$. pyogenes should be excluded from the genus Corynebacterium $(2,10,14,19,20,23,34)$. However, the exact taxonomic status of $C$. pyogenes has remained an enigma due to a lack of sufficient information about this organism. The objective of this investigation was to study the morphology, physiology, metabolism, nutrition, and biochemical characteristics of C. pyogenes to determine its taxonomic status. Based on the results of this study, we propose that $C$. pyogenes be transferred to the genus Actinomy-

$\dagger$ Article 10230 from the Michigan Agriculture Experiment Station. ces (38) as Actinomyces pyogenes (Glage) comb. nov.

(This work was presented in part at the 62 nd Annual Meeting of the Conference of Research Workers in Animal Disease, 9 to 10 November 1981, Chicago, Ill.)

\section{MATERIALS AND METHODS}

Bacterial strains. Since no type strain was designated for $C$. pyogenes at the time that this work was initiated in 1977, strain Glage C-100 (= NCTC $5224=$ ATCC 19411), which is the parent strain of the recently designated type strain (37) of $C$. pyogenes, was obtained from C. S. Cummins, Anaerobe Laboratory, Virginia Polytechnic Institute and State University, Blacksburg, and was used in this study. C. pyogenes strains NCDO 1903, NCDO 1906, NCDO 1909, NCDO 1910 , and NCDO 1911 were from the National Collection of Dairy Organisms, Reading, England, and were sent to us by D. J. Jayne Williams. The source of strain MSU 5 (= ATCC 33157) has been described previously (31). Strains Carter BT-34-49a, BT-337-76, and BT-400-76 were obtained from G. R. Carter of our department. Unless otherwise mentioned, most of the results were obtained with the three well-characterized and widely studied strains C-100, MSU 5, and 
TABLE.1. Acid production from various carbohydrates and biochemical characteristics of $C$ pyogenes

\begin{tabular}{|c|c|c|c|}
\hline \multirow[b]{2}{*}{ Test } & \multicolumn{3}{|c|}{ Results of: ${ }^{a}$} \\
\hline & $\begin{array}{c}\text { This study } \\
\text { (strain }^{\text {C-100) }}\end{array}$ & Roberts $^{c}$ & $\begin{array}{c}\text { Barksdale } \\
\text { et al. }{ }^{d}\end{array}$ \\
\hline Acid production from: & & & \\
\hline Adonitol & a & $17^{c}$ & ND \\
\hline Amygdalin & - & 0 & ND \\
\hline Arabinose & - & 37 & 0 \\
\hline Cellobiose & a & 50 & ND \\
\hline Dextrin & a & 76 & 100 \\
\hline Erythritol & a & 20 & ND \\
\hline Esculin & - & ND & ND \\
\hline Fructose & a & 83 & 100 \\
\hline Galactose & a & 53 & 100 \\
\hline Glucose & $\mathrm{a}$ & 100 & 100 \\
\hline Glycerol & - & 47 & 0 \\
\hline Glycogen & a & 77 & ND \\
\hline Hippurate & - & ND & ND \\
\hline Inositol & a & 21 & 62 \\
\hline Inulin & - & 0 & ND \\
\hline Maltose & $\mathrm{a}$ & 61 & 100 \\
\hline Lactose & $\mathrm{a}$ & 79 & 100 \\
\hline Mannitol & - & 10 & 0 \\
\hline Mannose & a & 43 & ND \\
\hline Melzitose & a & ND & ND \\
\hline Melibiose & - & ND & ND \\
\hline Raffinose & - & 0 & 0 \\
\hline Rhamnose & - & ND & 0 \\
\hline Ribose & $\mathbf{a}$ & ND & ND \\
\hline Salicin & - & 0 & ND \\
\hline Sorbitol & a & 6 & 0 \\
\hline Starch & a & 83 & 19 \\
\hline Sucrose & - & 44 & 29 \\
\hline Trehalose & a & 59 & 0 \\
\hline Xylose & a & 70 & 24 \\
\hline Gelatin hydrolysis & + & ND & 24 \\
\hline Milk & $A, C, D$ & A, C, D & $\mathrm{A}, \mathrm{C}, \mathrm{D}$ \\
\hline Indole & - & 0 & ND \\
\hline Nitrate & - & ND & ND \\
\hline Catalase & - & 0 & ND \\
\hline Hemolysis & + & 100 & 100 \\
\hline Urease & - & - & - \\
\hline
\end{tabular}

${ }^{a}$ Abbreviations: a, acid but no gas; w, weak acid; + , positive test; - , negative test; ND, not determined; A,C,D, acid, clot, and digestion of the clot.

${ }^{b}$ All other strains were identical to strain $\mathrm{C}-100$ in their biochemical characteristics, except that strain NCDO 1909 fermented mannitol and sucrose. Alanine, arginine, aspartate, glycine, and threonine were not fermented by any of the strains.

${ }^{c}$ The numbers are the percentages of positive strains of the 100 strains studied by Roberts (33).

${ }^{d}$ The numbers are the percentages of positive strains of the 21 strains studied by Barksdale et al. (3).

NCDO 1909. Of these, strains C-100 and MSU 5 were identical in all characteristics tested; NCDO 1909 was very similar to the other two strains except for some relatively minor differences, as noted below. All 10 strains were included in some critical experiments, such as those used to determine metabolic products and key biochemical characteristics.

Maintenance of cultures. Cultures were maintained on plates of tryptose agar (Difco Laboratories, Detroit, Mich.) supplemented with $5 \%$ sheep blood, as previously described (30).

Media. Serum-free medium (SFM), which was used in most of the experiments, contained (per $100 \mathrm{ml}$ ) 0.5 g of Trypticase (BBL Microbiology Systems, Cockeysville, Md.), $0.2 \mathrm{~g}$ of yeast extract (Difco), $0.4 \mathrm{~g}$ of glucose, $7.5 \mathrm{ml}$ of mineral solutions 1 and 2 of Caldwell and Bryant (7), $0.0002 \mathrm{~g}$ of hemin, $1.0 \mathrm{ml}$ of a volatile fatty acid solution (1 ml each of isobutyric, DL-2methyl butyric, and isovaleric acids and $1.6 \mathrm{ml}$ of acetic acid in $100 \mathrm{ml}$ of water), $2 \mathrm{ml}$ of $1 \mathrm{M}$ potassium phosphate buffer ( $\mathrm{pH} 7.0$ ), $0.05 \mathrm{~g}$ of cysteine hydrochloride, and $0.4 \mathrm{~g}$ of $\mathrm{NaHCO}_{3}$. All of the ingredients except cysteine and $\mathrm{NaHCO}_{3}$ were mixed in distilled water, the $\mathrm{pH}$ was adjusted to 6.5 with $2.5 \mathrm{~N} \mathrm{NaOH}$, and the preparation was dispensed into foam-plugged tubes (18 by $150 \mathrm{~mm} ; 9.5 \mathrm{ml} /$ tube) and sterilized by autoclaving at $121^{\circ} \mathrm{C}$ for $15 \mathrm{~min}$. The cysteine hydrochloride and $\mathrm{NaHCO}_{3}$ solutions were autoclaved separately and were added aseptically to the sterile medium immediately before inoculation. SFM agar medium contained SFM and $1.5 \mathrm{~g}$ of agar (Difco) per $100 \mathrm{ml}$ of medium. SFM agar plates were stored and incubated under $\mathrm{CO}_{2}$ to prevent aklalinization of the medium due to $\mathrm{CO}_{2}$ loss.

Anaerobic SFM, which in addition contained $0.0001 \%$ (wt/vol) resazurin (Eh indicator), was prepared by using Hungate anaerobic techniques, as modified by Holdeman et al. (22), and was dispensed under $100 \% \mathrm{CO}_{2}$ into sterile tubes $(18$ by $150 \mathrm{~mm} ; 10$ $\mathrm{ml} /$ tube) closed with butyl rubber stoppers.

The chemically defined medium (CDM) used for determining the inositol, vitamin, purine and pyrimidine, and peptide requirements for $C$. pyogenes growth was identical in composition to the medium previously described (30), except that inositol was replaced by $0.4 \mathrm{~g}$ of charcoal-treated Trypticase (17) per $\mathrm{ml}$, unless otherwise mentioned.

Vitamin requirements were detemined by adding one or more filter-sterilized vitamin solutions, as needed, to sterile CDM lacking vitamins.

The purine and pyrimidine requirements for $C$. pyogenes growth were determined by adding one or more sterile solutions of individual purines or pyrimidines or both to sterile CDM lacking purines and pyrimidines.

To study the $\mathrm{CO}_{2} / \mathrm{HCO}_{3}{ }^{-}$requirements of $C$. pyogenes, $\mathrm{NaHCO}_{3}^{-}$was deleted from anaerobic SFM, and dissolved $\mathrm{CO}_{2}$ was rigorously excluded from the medium as previously described by Dehority (15), except that the initial gas stripping was done at $\mathrm{pH} 5.5$. This experiment (see Table 2) was conducted in a BioFlo fermentor (model C30; New Brunswick Scientific Co., New Brunswick, N.J.) containing $550 \mathrm{ml}$ of medium. The gas flow rate was $600 \mathrm{ml} / \mathrm{min}$. The fermentor was sparged with $100 \% \mathrm{CO}_{2}, 100 \% \mathrm{~N}_{2}$, or $90 \% \mathrm{~N}_{2}-10 \% \mathrm{CO}_{2}$, as indicated below.

Fractionation of Trypticase. Charcoal-treated Trypticase was fractionated on a Sephadex G-25 (Pharmacia Fine Chemicals, Inc., Piscataway, N.J.) column (1.5 by $30 \mathrm{~cm}) . \mathrm{KPO}_{4}$ buffer $(50 \mathrm{mM}$, pH 7.0) was used as the eluant at a flow rate of $60 \mathrm{ml} / \mathrm{h}$. A $5-\mathrm{ml}$ portion of a $20 \%$ (wt/vol) Trypticase solution was applied to the 
TABLE 2. Effect of $\mathrm{CO}_{2} / \mathrm{HCO}_{3}{ }^{-}$on the growth of C. pyogenes ${ }^{a}$

\begin{tabular}{lcc}
\hline \multicolumn{1}{c}{ Gas phase } & $\begin{array}{c}\mathrm{HCO}_{3}^{-} \\
\text {added } \\
\text { (g/100 ml) }\end{array}$ & $A_{600}{ }^{b}$ \\
\hline $\mathrm{CO}_{2}$ & 0.4 & $1.60(26)$ \\
$\mathrm{N}_{2}$ & 0.006 & $\mathbf{0 . 3 2}(72)$ \\
$\mathrm{N}_{2}$ & 0.0 & $0.03(72)$ \\
$90 \% \mathrm{~N}_{2}-10 \% \mathrm{CO}_{2}$ & 0.0 & $1.35(30)$ \\
\hline
\end{tabular}

${ }^{a} C$. pyogenes was grown in SFM containing varying amounts of added $\mathrm{NaHCO}_{3}$ and was incubated under different gas phases.

${ }^{b}$ Growth was estimated by measuring $A_{600}$. The values in parentheses are the numbers of hours of incubation required for maximum absorbance.

column, and after the void volume had passed, 5-ml fractions of effluent were collected. The fractions were autoclaved for $10 \mathrm{~min}$ before they were added to CDM lacking Trypticase.

The amino nitrogen contents of the above-mentioned fractions were determined by the method of Rosen (35). A volume of each fraction was hydrolyzed with an equal volume of $12 \mathrm{~N} \mathrm{HCl}$ for $11 \mathrm{~h}$ at $121^{\circ} \mathrm{C}$. The average peptide size for each fraction was calculated by dividing the value for $\alpha$-amino nitrogen from the hydrolyzed fraction by the corresponding value for the unhydrolyzed sample.

Growth measurements. Growth was estimated by measuring the absorbance at $600 \mathrm{~nm}\left(A_{600}\right)$ with a Spectronic 20 spectrophotometer (Bausch \& Lomb,

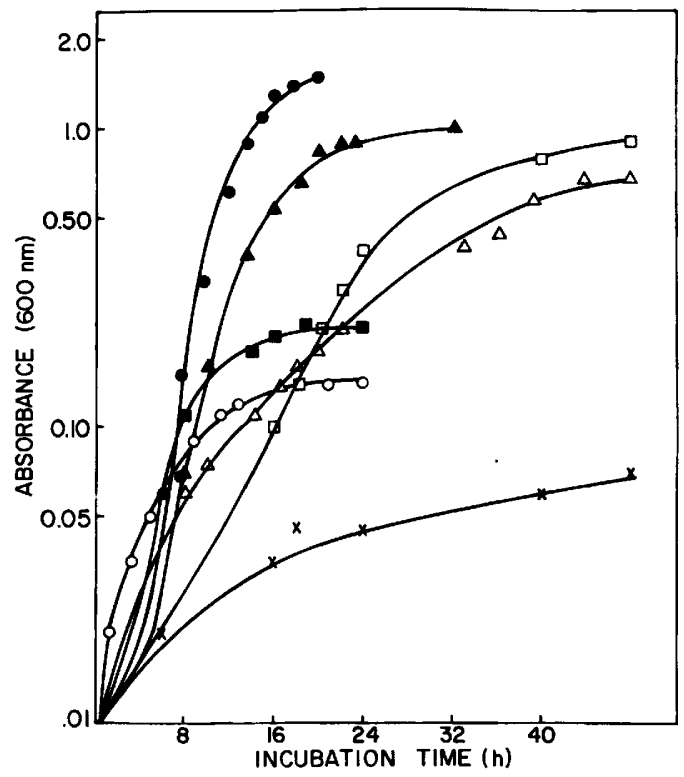

FIG. 1. Effects of various deletions from SFM on the growth of $C$. pyogenes strain MSU 5. Symbols: no deletion; $\boldsymbol{\Delta}$, minus Trypticase; $\boldsymbol{\nabla}$, minus yeast extract; $O$, minus glucose; $\triangle$, minus $\mathrm{NaHCO}_{3} ; \square$, minus hemin; $\times$, minus hemin and $\mathrm{NaHCO}_{3}$.

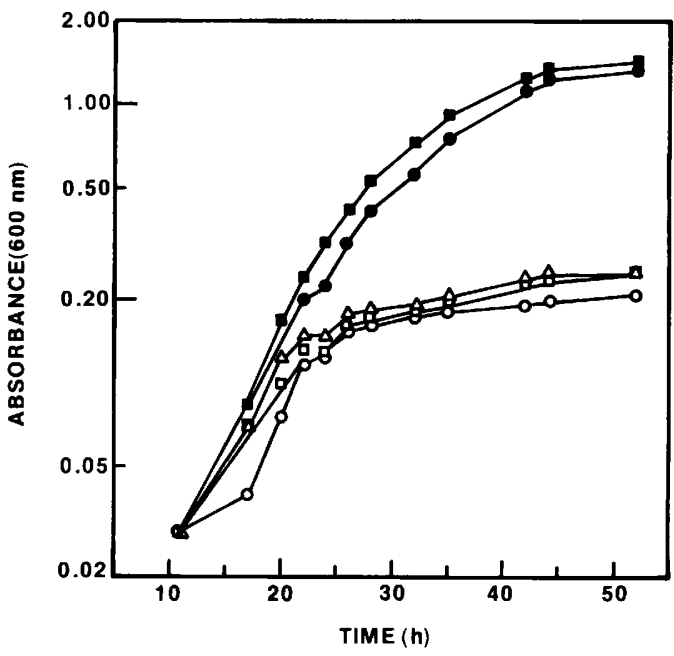

FIG. 2. Purine and pyrimidine requirements for growth of $C$. pyogenes strain MSU 5. Various bases were added to CDM lacking purines and pyrimidines. Symbols: a, complete complement of purines and pyrimidines; $\odot$, adenine and uracil; $\triangle$, adenine; $\square$, uracil; $O$, no addition.

Inc., Rochester, N.Y.). The mean absorance values for triplicate tubes are reported below. Other experiments (data not shown) showed good correlations among $A_{600}$ values, cell numbers, and dry weights of cells of strain MSU $5\left(A_{600}\right.$ of $1.0=1.83 \times 10^{9} \pm 0.08$ $\times 10^{9}$ cells per $\mathrm{ml}=0.45 \mathrm{mg}$ [dry weight]).

Preparation of inocula. Except for the nutritional experiments, cells grown in SFM at $37^{\circ} \mathrm{C}\left(A_{600}, 0.8\right)$ served as the inocula $(0.05 \mathrm{ml} / 10 \mathrm{ml}$ of medium). For

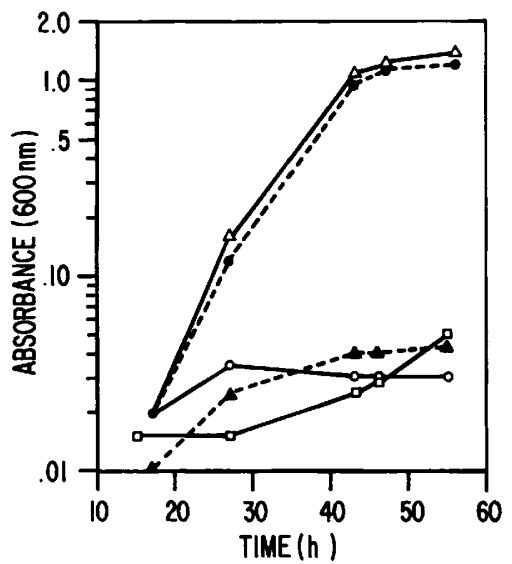

FIG. 3. Inositol requirement for growth. The basal medium used was CDM lacking Trypticase. In different experiments $1 \mathrm{mg}$ of inositol per $\mathrm{ml}, 1 \mathrm{mg}$ of lipoic acid per $\mathrm{ml}$, or $0.5 \mathrm{mg}$ of Tween 80 per $\mathrm{ml}$ was added. When Trypticase was added, it was at the same concentration as in CDM. Symbols: $\square$, no addition; $\triangle$, plus Trypticase;, plus inositol; $\bigcirc$, plus Tween $80 ; \boldsymbol{\Lambda}$, plus lipoic acid. 


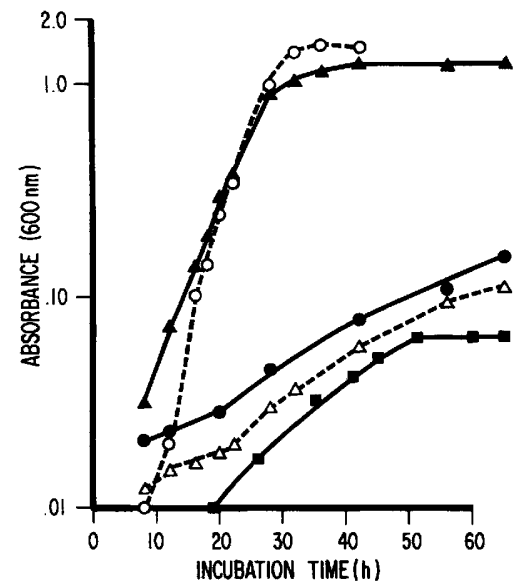

FIG. 4. Effects of deletions of various nitrogen sources from CDM on the growth of $C$. pyogenes strain MSU 5. Nitrogen sources were deleted either singly or in various combinations. Symbols: $\mathbf{D}$, minus Trypticase; 0 , minus Trypticase and cysteine; $\triangle$, minus Trypticase and amino acids; $\boldsymbol{\Lambda}$, minus amino acids; $O$, complete CDM.

nutritional experiments (see Fig. 1 through 5 and Tables 2 and 3), cells for inocula were grown at $37^{\circ} \mathrm{C}$ in CDM $\left(A_{600}, 0.4\right)$. Whenever possible, the organism was serially subcultured in a nutritional medium at least three times to minimize the effects of carry-over of any nutrients present in the original inoculum, and the results obtained after the third serial transfer are reported.

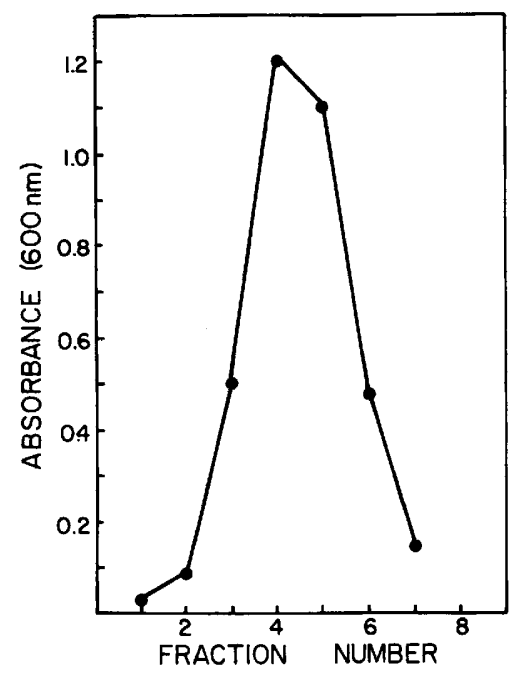

FIG. 5. Maximum growth of $C$. pyogenes strain MSU 5 in response to additions of various Trypticase fractions. Each fraction was added to CDM lacking Trypticase. Charcoal-treated Trypticase (15) was fractionated on a Sephadex G-25 column as described in the text.
Morphology. Cellular morphology was determined by examining wet mounts and Gram-stained smears of cells grown in SFM and on blood agar plates for 18 and $48 \mathrm{~h}$, respectively. Cell dimensions were measured with a calibrated ocular micrometer or were calculated from measurements made from photomicrographs of known magnification.

Ultrastructure was determined by examining electron micrographs of thin sections of cells harvested from a log-phase (12-h) culture of $C$. pyogenes grown in SFM. Cells were fixed by the method of Ryter and Kellenberger (36) and embedded in Epon.

Biochemical characteristics. The biochemical characteristics of $C$. pyogenes were determined under strictly anaerobic conditions by using the procedures described in the Anaerobe Laboratory Manual (22) and SFM lacking glucose as the basal medium. Each substrate was added to the basal medium as recommended by Holdeman et al. (22). All biochemical test media were inoculated with $0.05 \mathrm{ml}$ of a 24-h-old culture $\left(A_{600}, 1.5\right)$ of $C$. pyogenes grown in SFM and were incubated for $72 \mathrm{~h}$ (or longer as needed) at $37^{\circ} \mathrm{C}$. All biochemical tests were run in triplicate, and there was good reproducibility of the results among replicates.

Acid metabolic products. An analysis of acid metabolic end products was performed on the supernatants of SFM-grown cultures as previously described (32). A Varian model 2440 chromatograph fitted with a stainless steel column $(0.125$ in. [ $3.18 \mathrm{~mm}$ ] by $6 \mathrm{ft}$ [ $1.83 \mathrm{~m}])$ packed with $3 \%$ SP-1220-1\% $\mathrm{H}_{3} \mathrm{PO}_{4}$ on Chromosorb W-AW (Supelco, Bellefonte, Pa.) was used, with helium as the carrier gas at a flow rate of $25 \mathrm{ml} / \mathrm{min}$. The column temperature was $135^{\circ} \mathrm{C}$, the injection temperature was $165^{\circ} \mathrm{C}$, the detector current was 225 $\mathrm{mA}$, and the detector temperature was $160^{\circ} \mathrm{C}$. The packing used gave good resolution of formic acid from acetic acid.

Cytochrome measurements. The presence of cytochromes was determined by using dithionite-reduced

TABLE 3. Effects of vitamins on the growth of $C$. pyogenes

\begin{tabular}{lcc}
\hline \multirow{2}{*}{ Addition(s) } & \multicolumn{2}{c}{ Growth of: $^{b}$} \\
\cline { 2 - 3 } & $\begin{array}{c}\text { Strain } \\
\text { C-100 }\end{array}$ & $\begin{array}{c}\text { Strain } \\
\text { MSU 5 }\end{array}$ \\
\hline None & $0.02(45)$ & $0.17(46)$ \\
Riboflavin & $0.11(37)$ & $0.65(36)$ \\
$\begin{array}{l}\text { Nicotinic acid } \\
\text { Riboflavin + } \\
\quad \text { nicotinic acid }\end{array}$ & $0.05(38)$ & $0.10(50)$ \\
$\begin{array}{l}\text { Riboflavin + } \\
\quad \text { nicotinic acid + } \\
\quad \text { biotin + thiamine }\end{array}$ & $0.74(38)$ & $1.20(36)$ \\
Complete & $1.1 \quad(38)$ & \\
\hline
\end{tabular}

${ }^{a}$ None, CDM lacking vitamins; complete, vitamin mixture as in complete CDM. No vitamins or one or more vitamins were added to CDM lacking vitamins at the same concentrations used in CDM.

${ }^{b}$ Growth was measured by $A_{600}$, as described in the text. The values in parentheses are the numbers of hours of incubation required for maximum absorbance. 
minus air-oxidized difference spectra, as previously described (31). Hemes were extracted, the pyridine hemochromes were prepared as previously described (31), and the spectra of both the acid-acetone-soluble and insoluble fractions were determined.

\section{RESULTS}

Oxygen relationships. Although $C$. pyogenes has been described as facultatively anaerobic (34), the effect of oxygen on the growth of this organism has never been clearly defined. Therefore, $C$. pyogenes was grown in SFM under the following conditions: (i) strictly anaerobic conditions under $100 \% \mathrm{CO}_{2}$; (ii) aerobically in foamplugged vessels (incubated without shaking); and (iii) with vigorous continuous aeration by sparging with $95 \%$ air-5\% $\mathrm{CO}_{2}$. Growth was essentially identical $\left(A_{600}, 1.5 \pm 0.2\right)$ under all three conditions, and more than $90 \%$ of the glucose carbon utilized was recovered as organic acids. These results indicated that $C$. pyogenes obtains its energy for growth by fermentative metabolism.

Biochemical characteristics. A number of investigators have described the biochemical characteristics of $C$. pyogenes under aerobic growth conditions $(3,32,33,39)$. Since the results of our study indicated that $C$. pyogenes is an anaerobe from a metabolic standpoint, the biochemical characteristics of $C$. pyogenes (Table 1) were determined under strictly anaerobic conditions so that the results obtained would be comparable to those obtained with anaerobes $(22,38)$. Results obtained under aerobic conditions by Roberts (33) and Barksdale et al. (3) are also presented in Table 1 for comparative purposes. All strains of $C$. pyogenes were very similar in producing acid but not gas from a variety of carbohydrates. However, some strain variations in the fermentation of mannitol and sucrose were observed. Similar results were obtained by Roberts. About $10 \%$ of the strains studied by Roberts were positive for mannitol, and about $44 \%$ were positive for sucrose fermentation. All of the strains included in this study and in that of Roberts were negative for catalase and positive for gelatin liquefaction. Acid coagulation of milk followed by complete digestion of the clot was characteristic of all strains included in this study.

Acid metabolic products. It has been well established that metabolic products represent an important and stable basis upon which to differentiate fermentative bacteria (32). Furthermore, metabolic products are known to be similar among the strains within each species and are reproducible from culture to culture within a strain (26). Hence, in addition to the 10 strains included in this study, 9 additional strains of $C$. pyogenes were also included in this experiment.

Reddy et al. $(31,32)$ showed that in Trypticase broth and in brain heart infusion broth with no added $\mathrm{HCO}_{3}{ }^{-}$, the major product $(>1 \mathrm{meq} / 100$ $\mathrm{ml}$ ) of glucose fermentation by $C$. pyogenes is lactate and that acetate is a minor product $(<1$ $\mathrm{meq} / 100 \mathrm{ml}$ ). All strains examined in this study produced major amounts of lactate and minor amounts of acetate and succinate in brain heart infusion broth and in SFM lacking $\mathrm{HCO}_{3}{ }^{-}$. In SFM, succinate, acetate, and formate were the major products, and variable amounts of lactate were produced. The following acid fermentation products (in millimoles per 100 millimoles of glucose metabolized) were produced in SFM, in SFM lacking $\mathrm{HCO}_{3}{ }^{-}$, and in SFM lacking hemin by strain MSU 5: in SFM, formate (61), acetate (66), succinate (85), lactate (24), and pyruvate (3); in SFM lacking $\mathrm{HCO}_{3}{ }^{-}$, formate (0), acetate (4), succinate (22), lactate (141), and pyruvate (26); and in SFM lacking hemin, formate (5), acetate (46), succinate (47), lactate (88), and pyruvate (6.9). The $\mathrm{CO}_{2} / \mathrm{HCO}_{3}{ }^{-}$fixed in SFM was stoichiometric with the succinate formed. Results were similar with strains C-100 and NCDO 1909.

Cytochrome $b$ production. The presence or absence of different types of cytochromes is of some importance in bacterial taxonomy (27). Reddy et al. (31) previously reported the presence of a typical type $b$ cytochrome, but not of type $a$, type $c$, or other cytochromes, in cell extracts of strain MSU 5, as revealed by absorption maxima at 560, 530, and $428 \mathrm{~nm}$ in a dithionite-reduced minus air-oxidized difference spectrum. The difference spectrum of the pyridine hemochrome derivative of the acid-acetone-extractable heme from $C$. pyogenes showed absorption maxima at 556, 521, and 418 $\mathrm{nm}$, which are characteristic of protoheme, the prosthetic group of cytochrome $b$. The presence of cytochrome $b$ has also been demonstrated in strain ATCC 19411 and in a freshly isolated MSU SS 7-74, C. pyogenes strain, (M. Kao and C. A. Reddy, unpublished data). Preliminary results showed that the cytochrome $b$ in $C$. pyogenes mediates the reduction of fumarate to succinate, with reduced nicotinamide adenine dinucleotide as the electron donor (Cornell and Reddy, unpublished data).

Nutrition. Some nutritional features of $C$. pyogenes MSU 5 are shown in Fig. 1. The results with strains C-100 and NCDO 1909 were identical. $C$. pyogenes appears to require a fermentable carbohydrate for growth since minimal growth was obtained in SFM lacking glucose. Deletion of yeast extract from SFM decreased growth by $\sim 80 \%$. Growth was negligible after simultaneous deletion of hemin and $\mathrm{HCO}_{3}{ }^{-}$. Single deletions of hemin and $\mathrm{HCO}_{3}{ }^{-}$resulted in $\sim 35$ and $50 \%$ decreases in growth, respectively (Fig. 1). These results suggested that hemin and 
$\mathrm{HCO}_{3}{ }^{-}$are stimulatory for growth and that each of these compounds could partially substitute for the other. The doubling time in SFM was 1.6 $\mathrm{h}$, compared with $8.4 \mathrm{~h}$ in SFM lacking $\mathrm{HCO}_{3}{ }^{-}$ and $4.1 \mathrm{~h}$ in SFM lacking hemin. Rigorous exclusion of $\mathrm{HCO}_{3}{ }^{-}$from the medium by using the procedures of Dehority (15) showed that $\mathrm{HCO}_{3}{ }^{-}$is an obligate requirement for the growth of $C$. pyogenes (Table 2). There was no detectable growth in anerobic SFM lacking $\mathrm{HCO}_{3}{ }^{-}$ when a $100 \% \mathrm{~N}_{2}$ gas phase was used. Growth was near normal in the latter medium when a $90 \% \mathrm{~N}_{2}-10 \% \mathrm{CO}_{2}$ gas mixture was substituted for $100 \% \mathrm{~N}_{2}$. Appreciable growth was observed in modified SFM containing only $0.006 \%$ (wt/ vol) $\mathrm{HCO}_{3}{ }^{-}$.

Deletion of vitamins from CDM resulted in negligible growth (Table 3 ). Single additions of nicotinic acid and riboflavin produced little improvement in growth. Combined addition of riboflavin and nicotinic acid gave only $53 \%$ of the growth observed in complete medium. Strain MSU 5 produced as much growth with riboflavin and nicotinic acid as strain C-100 did with riboflavin, nicotinic acid, biotin, and thiamin. Results with strain NCDO 1909 were identical to those with strain C-100.

Deletion of purines and pyrimidines from CDM resulted in very little growth of strain MSU 5 (Fig. 2). Single additions of adenine and uracil did not appreciably improve growth. Combined addition of adenine and uracil produced growth comparable to that observed in CDM. Very similar results were obtained with strain C-100, but strain NCDO 1909 did not show a requirement for purines or pyrimidines for growth.

Inositol was obligatorily required for growth of $C$. pyogenes strain MSU 5 (Fig. 4). Lipoic acid and Tween 80 were not required for growth. Trypticase appeared to relieve the requirement for inositol. Results were identical with strains C-100 and NCDO 1909.

The effects of deletions of various nitrogen sources from CDM on the growth of $C$. pyogenes strain MSU 5 are shown in Fig. 4. Little growth was observed when Trypticase was deleted from CDM in spite of the fact that the latter medium contained a full complement of amino acids. These results suggested that $C$. pyogenes requires peptides for growth. When charcoaltreated Trypticase was fractionated on a Sephadex G-25 column and each fraction was added individually to tubes containing CDM lacking Trypticase, fraction 4 , which had a mean peptide size of 1.5 amino acids, gave the optimal growth response (Fig. 5). Strains C-100 and NCDO 1909 were similar to strain MSU 5 in showing a peptide requirement for growth.

Morphology. After $24 \mathrm{~h}$ of incubation on an- aerobic blood agar plates, colonies were $\beta$ hemolytic, smooth, and circular, with slightly granular surfaces and entire edges. These colonies were convex and translucent to white under reflected light. None of the strains produced a filamentous microcolony under the conditions used. After 48 to $72 \mathrm{~h}$, the colonies were 0.5 to $1.5 \mathrm{~mm}$ in diameter, low convex to convex, circular, opaque, white, and soft, with entire edges. Typically, the zones of $\beta$-hemolysis were two to three times the diameters of the colonies.

Colonies on anaerobic SFM agar plates were 1.5 to $3 \mathrm{~mm}$ in diameter after 24 to $36 \mathrm{~h}$ of incubation. Thus, the colonies on SFM developed faster and were typically larger than the colonies on blood agar plates. These colonies were white, raised, translucent, smooth, soft, and circular, with entire to slightly uneven edges.

All strains examined were gram positive, nonmotile, and non-acid fast and showed a certain degree of pleomorphism in different growth media (Fig. 6). Cells from colonies picked from blood agar plates occurred mostly singly and in pairs (" $\mathrm{V}$ " and " $\mathrm{T}$ " formations) and were 0.2 to 0.5 by 0.6 to $1.9 \mu \mathrm{m}$ (Fig. 6A). Cells grown in SFM (Fig. 6B) were 0.4 to 0.9 by 1.0 to $2.5 \mu \mathrm{m}$ and occurred singly, in pairs ( $\mathrm{V}$ and $\mathrm{T}$ formations and some palisades), and often as threedimensional clusters with apparent branching. Long, multibranched forms were not observed. Brown and Orcutt (4) often observed a mixture of rod-shaped, fusiform, diphtheroid, streptococcal, and some filamentous and branching forms. Some strains tended to "assume more of one form and others another." Streptococcal forms in small clumps and short crooked chains were also observed (4).

Ultrastructure. Transmission electron microscopy of thin sections of $C$. pyogenes showed ultrastructural details typical of gram-positive bacteria. The cells were predominantly rod shaped, although not infrequently rounded forms were also observed. In addition, clubshaped cells (Fig. 7A) and straight to slightly curved rods were seen (Fig. 7B and D). The cytoplasm was granular and packed with ribosomes (Fig. 7B). The nuclear material appeared to be distributed relatively diffusely in the cytoplasm. Division was by septum formation (Fig. $7 \mathrm{~A}$ and B). Mesosome-like membranous structures were seen in some cells (Fig. 7B and C). The thickness of the cell wall was 29 to $30 \mathrm{~nm}$. The multilayered appearance of the cell wall was rather characteristic (Fig. 7C and D); there was an inner thin darkly staining layer and an outer, thicker, amorphous, lightly staining layer. Thus, the ultrastructure of $C$. pyogenes was very similar to that reported for several Actinomyces species (38). 

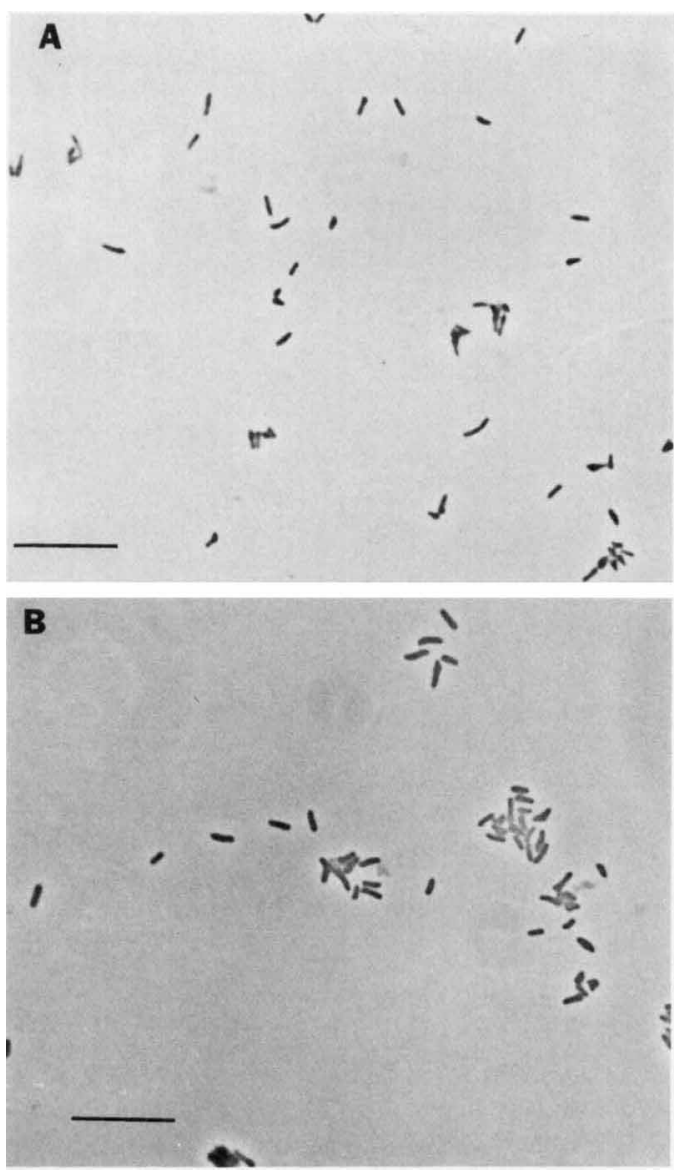

FIG. 6. (A) Photomicrograph of a wet mount preparation of cells of $C$. pyogenes from a 48-h-old colony on a blood agar plate. Bar $=10 \mu \mathrm{m}$. Note the rodshaped to coccobacillary forms occurring singly, in pairs ( $\mathrm{V}$ and $\mathrm{T}$ ), in palisades, and in small clumps. Some distinct club-shaped cells are also present. (B) Photomicrograph of a wet mount preparation of $C$. pyogenes cells grown in SFM broth for $18 \mathrm{~h}$. Bar $=10$ $\mu \mathrm{m}$. Note that the cells are generally thicker and longer and have a greater tendency for clumping than the cells grown on blood agar plates.

\section{DISCUSSION}

The results of numerous investigations have revealed that $C$. pyogenes is distinctly different from $C$. diphtheriae and related animal-pathogenic corynebacteria in serology (11), in not containing mycolic acids (18), and on the basis of numerical taxonomy $(14,20,23)$. The cell walls of $C$. pyogenes differ from those of $C$. diphtheriae and related animal corynebacterial species in containing lysine instead of mesodiaminopimelic acid and in containing rhamnose and glucose instead of arabinose and galactose as the major cell wall sugars $(11,13)$. Experimental results have also shown that $C$. pyogenes differs from $C$. diphtheriae and related corynebacteria in being catalase negative, in liquefying gelatin, in causing acid coagulation and peptonization of litmus milk, and in nutrition. Furthermore, depending on the $\mathrm{CO}_{2} / \mathrm{HCO}_{3}{ }^{-}$concentration in the medium, $C$. pyogenes produces lactate or succinate as the major product of glucose fermentation but not propionic acid. In contrast, $C$. diphtheriae and related organisms produce propionate as a major product $(32)$. The results of our study indicate that $C$. pyogenes obtains energy for growth primarily by fermentation. On the other hand, $C$. diphtheriae can grow fermentatively under anaerobic conditions and by aerobic respiration in an oxygen atmosphere (2). Based on these findings, we can safely conclude that $C$. pyogenes has little in common with the type species $C$. diphtheriae and related animal-pathogenic bacteria and should be excluded from the genus Corynebacterium, as previously suggested by a number of other investigators $(2,3,32,34)$.

Previous studies have shown that the cell wall composition of $C$. pyogenes is similar to that of Streptococcus group G (Table 4) and that these two organisms share a cell wall polysaccharide antigen $(3,11)$ and ferment similar varieties of carbohydrates (3). Based on these results, Barksdale (2) suggested that $C$. pyogenes taxonomically belongs in the genus Streptococcus, specifically in Lancefield group G (16). However, the results of our study, as well as those of other recent investigations (24), show that $C$. pyogenes is different from Streptococcus group G. Whereas strains of Streptococcus group G, like most other streptococci, are homofermentative lactic acid bacteria, $C$. pyogenes carries out a homolactic acid type of fermentation only in media low in bicarbonate. In contrast, in media containing normal levels of bicarbonate $(0.4 \mathrm{~g} /$ $100 \mathrm{ml}), C$. pyogenes produces major amounts of succinate, acetate, formate, and lactate. This dramatic shift in fermentation depending on the presence of biocarbonate is not known to be exhibited by streptococci (16). Our results show that the amount of $\mathrm{CO}_{2} / \mathrm{HCO}_{3}{ }^{-}$fixed is stoichiometric with the succinate formed by $C$. pyogenes, whereas $\mathrm{CO}_{2}$ fixation to succinate has not been shown for streptococci. The latest edition of Bergey's Manual of Determinative Bacteriology considers the absence of cytochromes to be a characteristic of the genus Streptococcus (16). In contrast, $C$. pyogenes is known to contain cytochrome $b$ (31). The guanine-plus-cytosine content of the deoxyribonucleic acid is $\sim 56$ to 58 $\mathrm{mol} \%$, which is quite different from the value of 41 mol \% reported for Streptococcus group G (Table 5). Therefore, it is obvious that $C$. pyogenes is distinctly different from Streptococcus group G. 

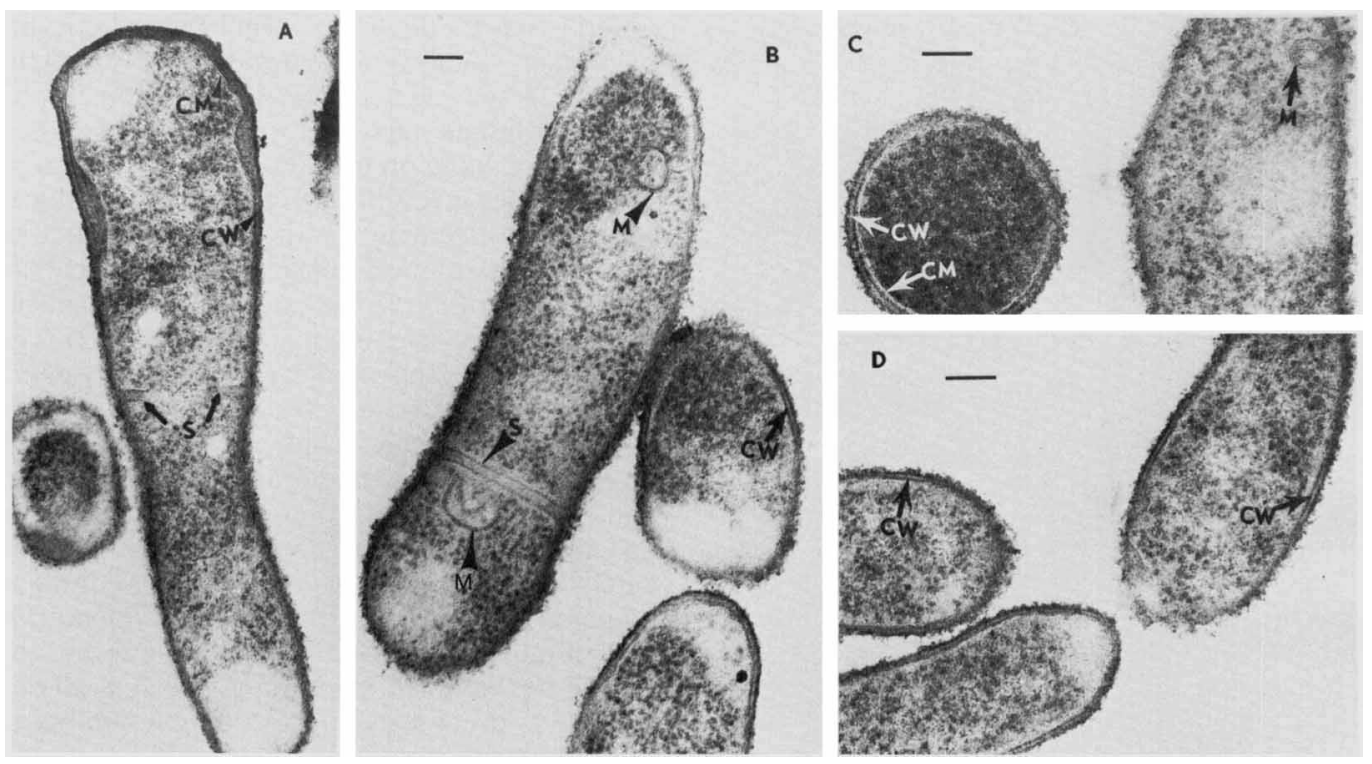

FIG. 7. Thin-section electron micrographs of cells of $C$. pyogenes strain MSU 5 grown in SFM for $12 \mathrm{~h}$. Bar $=$ $0.15 \mu \mathrm{m}$. Abbreviations: CM, cell membrane; CW, cell wall; S, septum; M, mesosome-like organelle. (A) Typical club-shaped (coryneform) cells showing clear resolution of the cell wall and cell membrane. Note septal initiation. (B) Cell showing fully formed septum and mesosome-like membranous structures. (C) Transverse section of a cell showing double-track appearance of the cell wall observed in most cells, including some cells in (B) and (D). (D) Angled or V-shaped arrangement of the cells.

The production of formate, acetate, succinate, and lactate as products of glucose fermentation is reported to be an important characteristic of Actinomyces species $(6,38,39)$. A substantial decrease in succinate production and a corresponding increase in lactate production are observed when Actinomyces species are grown in media containing no added $\mathrm{HCO}_{3}{ }^{-}(22,28)$. Our results show that $C$. pyogenes is identical to members of the genus Actinomyces in the types of fermentation products produced in different media.

The biochemical characteristics (Table 1) of

TABLE 4. Cell wall composition of $C$. pyogenes compared with the compositions of $A$. bovis, $C$. diphtheriae, and Streptococcus group G cell walls ${ }^{a}$

\begin{tabular}{|c|c|c|}
\hline Organism & Sugars $^{b}$ & Amino acids ${ }^{b}$ \\
\hline $\begin{array}{l}\text { C. pyogenes } \\
\text { A. bovis } \\
\text { C. diphtheriae } \\
\text { Streptococcus } \\
\quad \text { group } \mathrm{G}\end{array}$ & $\begin{array}{l}\text { Rha, Glc, } \pm \text { Man } \\
\text { Rha, 6-D-Tal, Fuc } \\
\text { Ara, Gal, Man } \\
\text { Rha, Gal }\end{array}$ & $\begin{array}{l}\text { Ala, Glu, Lys } \\
\text { Ala, Asp, Lys } \\
\text { Ala, Glu, m-DAP } \\
\text { Ala, Glu, Lys }\end{array}$ \\
\hline
\end{tabular}

${ }^{a}$ Data from references 3,11 , and 13 .

${ }^{b}$ Abbreviations: Rha, rhamnose; Glc, glucose; Man, mannose; 6-D-tal, 6-deoxytalose; Fuc, fucose; Ara, arabinose; Gal, galactose; Ala, alanine; Glu, glutamate; Lys, lysine; Asp, aspartate; $m$-DAP, mesodiaminopimelate.
C. pyogenes appear to be very similar to those of Actinomyces bovis $(38,39)$, except that $C$. pyogenes is hemolytic and actively proteolytic, as evidenced by its ability to hydrolyze gelatin and casein (milk clot), and produces a soluble toxin. Some strains of Actinomyces israelii are known to be proteolytic, as evidenced by zones of hydrolysis on gelatin agar plates (39). C. pyogenes strains showed an obligate requirement for $\mathrm{HCO}_{3}{ }^{-}$for growth (Table 2), which is in agreement with the finding that $\mathrm{HCO}_{3}{ }^{-}$is known to be highly stimulatory or required for the growth of Actinomyces species (39). Furthermore, the fact that $C$. pyogenes and $A$. israelii are the only two bacteria that have been shown to require inositol for growth $(9 ; \mathrm{V}$. B. D. Skerman, Ph.D. thesis, University of Reading, Reading, England, 1966) and the fact that the presence of a type $b$ cytochrome has been demonstrated in both $C$. pyogenes and Actinomyces species $(31,40)$ support the concept that these two groups are related to each other. Our results indicate that $C$. pyogenes is an aerotolerant anaerobe. All Actinomyces species except Actinomyces naeslundii are also aerotolerant anaerobes in that they can grow in air but are not known to utilize oxygen as a terminal electron acceptor in their metabolism. In contrast, $A$. israelii (originally described as $A$. naeslundii) appears to utilize oxygen as a terminal electron 
TABLE 5. Comparative guanine-plus-cytosine contents of $C$. pyogenes, certain corynebacteria, $A$. bovis, and Streptococcus group G

\begin{tabular}{lcc}
\hline \multicolumn{1}{c}{ Organism } & $\begin{array}{c}\text { Guanine-plus- } \\
\text { cytosine } \\
\text { content } \\
\text { (mol \%) }\end{array}$ & Reference(s) \\
\hline $\begin{array}{l}\text { C. pyogenes } \\
\text { C. pseudotuber- } \\
\quad \text { culosis }\end{array}$ & $56.3-57.7$ & 24,34 \\
$\begin{array}{l}\text { C. haemolyticum } \\
\begin{array}{l}\text { C. diphtheriae } \\
\text { Streptococcus }\end{array}\end{array}$ & $52.5-53.2$ & 21,24 \\
$\quad$ group G & $48-49$ & 24 \\
A. bovis & $51.9-41.0$ & 21 \\
\hline
\end{tabular}

acceptor when glucose is metabolized in air (6). The cell wall composition and the guanine-pluscytosine content of the deoxyribonucleic acid of $C$. pyogenes are very similar to those of $A$. bovis, the type species of Actinomyces (Tables 4 and 5). The cellular and colonial morphologies and the ultrastructure of $C$. pyogenes (see above) are also very similar to those of Actinomyces species, especially $A$. bovis and Actinomyces odontolyticus (39). Serological cross-reaction between $C$. pyogenes and $A$. odontolyticus has also been reported (39).

It is obvious from the discussion above that $C$. pyogenes is similar to members of the genus Actinomyces in a number of major characteristics. Therefore, it appears appropriate to transfer $C$. pyogenes to the genus Actinomyces, as previously suggested by Slack and Gerencser (39) and Reddy and Kao (32). Furthermore, individual properties of $C$. pyogenes distinguish it from the other currently recognized members of the genus Actinomyces (Table 6). Therefore, assignment of separate species status to $C$. pyogenes within the genus Actinomyces appears to be justified.

We propose that $C$. pyogenes be transferred to the genus Actinomyces and be renamed Actinomyces pyogenes (Glage) comb. nov. A comprehensive description of this organism, based on our results and those of other investigators, follows.

Actinomyces pyogenes (Glage) comb. nov. (Gr. n. pyum pus; Gr. v. gennaio to produce; M. L. adj. pyogenes pus-producing). Gram-positive, nonmotile, non-sporeforming coccobacilli and short rods that occur singly, in pairs $(\mathrm{V}, \mathrm{T}$, and palisade formations), or as clusters. Short diphtheroid forms with clubs are also seen. Streptococcal forms in small clumps and short crooked chains are occasionally observed (4). Cells vary in shape and size ( 0.2 to 0.9 by 0.3 to $2.5 \mu \mathrm{m}$ ) in different media. Cells from 24-h-old broth cultures are gram positive, but cells from older cultures may be gram variable. The cell wall ultrastructure is typical of gram-positive bacteria. The cell walls are 29 to $30 \mathrm{~nm}$ thick and have a characteristic double-track appearance.

Pinpoint, $\beta$-hemolytic colonies occur on sheep blood agar after $24 \mathrm{~h}$ of incubation. The zones of hemolysis are typically two to three times the diameter of the colony. After 48 to $72 \mathrm{~h}$, the colonies $(0.5$ to $1.5 \mathrm{~mm})$ appear convex, circular, opaque, white, and soft, with entire edges. Colonies develop faster and are bigger (1.5 to 3.0 mm) on SFM agar plates.

Good growth occurs under aerobic and strictly anaerobic conditions. Metabolism is strictly fermentative. Acid but not gas is produced from glucose, fructose, galactose, lactose, cellobiose, trehalose, maltose, melzitose, mannose, glycogen, dextrin, xylose, and starch. The fermentation of adonitol, arabinose, erythritol, glycerol, sucrose, mannitol, and sorbitol varies with the strain. No acid from amygdalin, esculin, melibiose, raffinose, rhamnose, or salicin. Alanine, arginine, aspartate, glycine, and threonine are not fermented. Most strains are catalase negative (32), although one strain studied by Cummins (12) has been reported to be catalase positive. Acid clotting and digestion of clots in litmus milk and liquefaction of gelatin are characteristic of all strains. Nitrates are not reduced, and indole is not produced. Optimum temperature, $37^{\circ} \mathrm{C}$; temperature range, 20 to $40^{\circ} \mathrm{C}$.

Lactic acid is the primary metabolic product in brain heart infusion or tryptose broth with no added $\mathrm{HCO}_{3}{ }^{-}$; acetate is a minor product. Glucose is fermented in the presence of $\mathrm{CO}_{2} / \mathrm{HCO}_{3}{ }^{-}$ and yields succinate, acetate, formate, and lactate as major products. For each $1 \mathrm{~mol}$ of $\mathrm{CO}_{2} /$ $\mathrm{HCO}_{3}{ }^{-}$fixed, $1 \mathrm{~mol}$ of succinate, $1 \mathrm{~mol}$ of acetate, and $1 \mathrm{~mol}$ of formate are produced. In identical media without added biocarbonate or hemin, lactate is the major product, and smaller amounts of acetate, succinate, and formate are produced.

$\mathrm{CO}_{2} / \mathrm{HCO}_{3}{ }^{-}$is required for growth. Hemin is highly stimulatory or required for growth. Peptides are required for growth even in the presence of a complete complement of 20 amino acids and $\left(\mathrm{NH}_{4}\right)_{2} \mathrm{SO}_{4}$. Inositol can replace the peptide requirement for growth. Riboflavin and nicotinic acid are required for optimal growth. Adenine and uracil are required for optimal growth of some strains.

Characteristic cell wall sugar components are rhamnose and glucose, and the major diamino acid of peptidoglycan is lysine $(11,13)$. No mycolic acids are present (18).

Culture filtrates are fatal to mice and rabbits after intravenous injection. The soluble hemolysin produced is active against human, guinea pig, sheep, horse, and rabbit erythrocytes. Both 


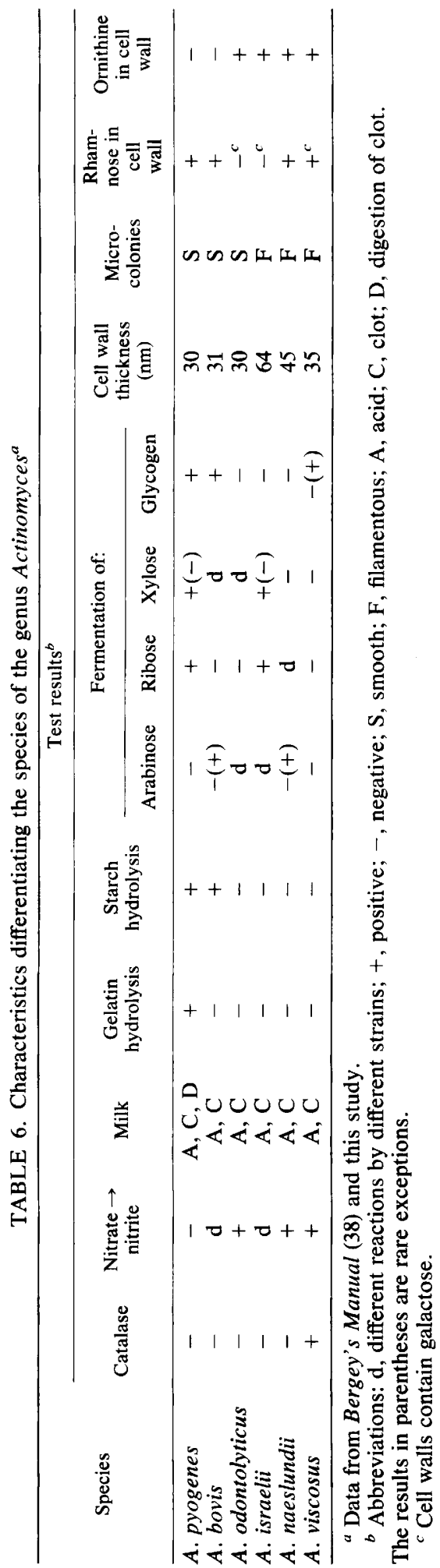

toxic and hemolytic activities of crude cell extracts are neutralized by antitoxin (25).

The guanine-plus-cytosine content of the deoxyribonucleic acid is 56 to $58 \mathrm{~mol} \%$. This organism is frequently isolated from a wide variety of pyogenic disease conditions in many species of domestic animals and in humans $(1,5$, $8,29,41)$. Presumably, $C$. pyogenes occurs as a commensal organism on the mucous surfaces of warm-blooded animals (8).

Type strain (37): ATCC 19411 (= NCTC 5224 $=\mathrm{C}-100$ ).

\section{ACKNOWLEDGMENTS}

We thank C. S. Cummins, D. J. Jayne Williams, and G. R. Carter for supplying various strains of $C$. pyogenes. We acknowledge H. S. Pankratz for taking the electron micrographs.

\section{ADDENDUM IN PROOF}

While this paper was in press, Collins et al. published a paper (M. D. Collins, D. Jones, R. M. Kroppenstedt, and K. H. Schleifer, J. Gen. Microbiol. 128:335-341, 1982) which strongly supports our proposal for the reclassification of $C$. pyogenes in the genus Actinomyces. These investigators, in agreement with the earlier results of Julak et al. (24), showed that tetradecanoic and hexadecanoic acids are the predominant fatty acids in the whole-organism methanolysates of $C$. pyogenes, although large amounts of octadecenoic acid (18:1 $\omega 9)$ are also present. Furthermore, tetrahydrogenated menaquinone with 10 isoprene units was shown to be the predominant quinone in $C$. pyogenes. These results constitute further evidence that $C$. pyogenes does not belong in the genus Corynebacterium, that this organism is distinct from Corynebacterium haemolyticum and streptococcus group $\mathrm{G}$, and that it is closely related to $A$. bovis. In another paper, G. M. Schofield and K. M. Schaal (J. Gen. Microbiol. 127:237-259, 1981), showed, on the basis of numerical taxonomy, a close relationship between $C$. pyogenes and $A$. bovis. Thus, there is growing evidence which justifies our proposal for reclassifying $C$. pyogenes as $A$. pyogenes.

\section{REPRINT REQUESTS}

Address reprint requests to: C. A. Reddy, Department of Microbiology and Public Health, Michigan State University, East Lansing, MI 48824.

\section{LITERATURE CITED}

1. Ballard, D. O., A. E. Upsher, and D. B. Seeley. 1947. Infection with Corynebacterium pyogenes in man. Am. J. Clin. Pathol. 17:209-215.

2. Barksdale, L. 1970. Corynebacterium diphtheriae and its relatives. Bacteriol. Rev. 34:368-422.

3. Barksdale, W. L., K. Li, C. S. Cummins, and H. Harris. 1957. The mutation of Corynebacterium pyogenes to Corynebacterium hemolyticum. J. Gen. Microbiol. 16:749-758.

4. Brown, J. H., and M. L. Orcutt. 1920. A study of Bacillus pyogenes. J. Exp. Med. 32:219-248.

5. Bruner, D. W., and J. H. Gillespie. 1973. Hagan's infectious diseases of domestic animals, 6th ed. Cornell University Press, Ithaca, N.Y.

6. Buchanan, B. B., and L. Pine. 1967. Path of glucose 
breakdown and cell yields of a facultative anaerobe, Actinomyces naeslundii. J. Gen. Microbiol. 46:225-236.

7. Caldwell, D. R., and M. P. Bryant. 1966. Medium without rumen fluid for nonselective enumeration and isolation of rumen bacteria. Appl. Microbiol. 14:794-801.

8. Chlosta, E. M., G. K. Richards, E. Wagner, and J. F. Holland. 1970. An opportunistic infection with Corynebacterium pyogenes producing empyema. Am. J. Clin. Pathol. 53:167-170.

9. Christie, A. O., and J. W. Porteus. 1962. The growth factor requirements of the Wills strain of Actinomyces israelii growing in a chemically defined medium. J. Gen. Microbiol. 28:455-460.

10. Collins, M. D., T. Pirouz, M. Goodfellow, and D. E. Minnikin. 1977. Distribution of menaquinones in actinomycetes and corynebacteria. J. Gen. Microbiol. 100:221230.

11. Cummins, C. S. 1962 . Chemical composition and antigenic structure of cell walls of Corynebacterium, Mycobacterium, Nocardia, Actinomyces and Arthrobacter. J. Gen. Microbiol. 28:35-50.

12. Cummins, C. S. 1971. Catalase activity in Corynebacterium pyogenes. Can. J. Microbiol. 17:1001-1002.

13. Cummins, C. S., and H. Harris. 1958. Studies on the cell wall composition and taxonomy of Actinomycetales and related groups. J. Gen. Microbiol. 18:173-179.

14. Davis, G. H., and K. G. Newton. 1969. Numerical taxonomy of some named coryneform bacteria. J. Gen. Microbiol. 56:195-214.

15. Dehority, B. A. 1971. Carbon dioxide requirement of various species of rumen bacteria. J. Bacteriol. 105:70-76.

16. Deibel, R. H., and H. W. Seeley, Jr. Streptococcaceae fam. nov, p. 490-508. In R. E. Buchanan and N. E. Gibbons (ed.), Bergey's manual of determinative bacteriology, 8th ed. The Williams \& Wilkins Co., Baltimore.

17. Ford, J. E., K. D. Perry, and C. A. E. Briggs. 1958. Nutrition of lactic acid bacteria isolated from the rumen. J. Gen. Microbiol. 18:273-284.

18. Goodfellow, M., M. D. Collins, and D. E. Minnikin. 1976. Thin-layer chromatographic analysis of mycolic acids and other long-chain components in whole-organism methanolysates of coryneform and related taxa. J. Gen. Microbiol. 96:351-358.

19. Gordon, R. E. 1966. Some strains in search of a genusCorynebacterium, Mycobacterium, Nocardia or what? J. Gen. Microbiol. 43:329-343.

20. Harrington, B. J. 1966. A numerical taxonomic study of some corynebacteria and related organisms. J. Gen. Microbiol, 45:31-40.

21. Hill, L. R. 1966. An index to deoxyribonucleic acid base composition of bacterial species. J. Gen. Microbiol. 44:419-437.

22. Holdeman, L. V., E. P. Cato, and W. E. C. Moore (ed.). 1977. Anaerobe laboratory manual, 4th ed. Virginia Polytechnic Institute and State University, Blacksburg.

23. Jones, D. 1975. A numerical taxonomic study of coryneform and related bacteria. J. Gen. Microbiol. 87:51-96.
24. Julak, J., M. Mara, B. Potuznikova, and S. Zadrasil. 1978. Contribution to the taxonomy of haemolytic corynebacteria. Folia Microbiol. 23:229-235.

25. Lovell, R. 1944. Further studies on the toxin of Corynebacterium pyogenes. J. Pathol. Bacteriol. 56:525-529.

26. Moore, W. E. C. 1970 . Relationship of metabolic products to taxonomy of anaerobic bacteria. Int. J. Syst. Bacteriol. 20:535-538.

27. Myer, D. J., and C. W. Jones. 1973. Distribution of cytochromes in bacteria: relationship to general physiology. Int. J. Syst. Bacteriol. 23:459-367.

28. Pine, L., and A. Howell, Jr. 1956. Comparison of physiological and biochemical characters of Actinomyces spp. with those of Lactobacillus bifidus. J. Gen. Microbiol. 15:428-445.

29. Potocka, F., A. Soucek, and M. Mara. 1960. New observations on biological properties and toxigenesis of atypical hemolytic corynebacteria isolated from humans. J. Hyg. Epidemiol. Microbiol. Immunol. 4:307-308.

30. Reddy, C. A., C. P. Cornell, and A. M. Fraga. 1980. Chemically defined growth medium for Corynebacterium pyogenes. Am. J. Vet. Res. 40:843-845.

31. Reddy, C. A., C. P. Cornell, and M. Kao. 1977. Hemindependent growth stimulation and cytochrome synthesis in Corynebacterium pyogenes. J. Bacteriol. 130:965-967.

32. Reddy, C. A., and M. Kao. 1978. Value of acid metabolic products in identification of certain corynebacteria. J. Clin. Microbiol. 7:428-433.

33. Roberts, R. J. 1968. Biochemical reactions of Corynebacterium pyogenes. J. Pathol. Bacteriol. 95:127-130.

34. Rogosa, M., C. S. Cummins, R. A. Lelliott, and R. M. Keddie. 1974. Coryneform group of bacteria, p. 599-632. In R. E. Buchanan and N. E. Gibbons (ed.), Bergey's manual of determinative bacteriology, 8 th ed. The Williams \& Wilkins Co., Baltimore.

35. Rosen, H. 1957. A modified ninhydrin colorimetric analysis for amino acids. Arch. Biochem. Biophys. 67:10-15.

36. Ryter, A., and E. Kellenberger. 1958. Etude au microscope electronique de plasmas contenant de l'acide désoxyribonucléique. I. Les nucléoides des bactéries en croissance active. Z. Naturforsch. Teil B 13:597-605.

37. Skerman, V. B. D., V. McGowan, and P. H. A. Sneath (ed.). 1980. Approved lists of bacterial names. Int. J. Syst. Bacteriol. 30:225-420.

38. Slack, J. M. 1974. Actinomycetaceae, p. 659-681. In R. E. Buchanan and N. E. Gibbons (ed.), Bergey's manual of determinative bacteriology, 8th ed. The Williams \& Wilkins Co., Baltimore.

39. Slack, J. M., and M. A. Gerencser. 1975. Actinomyces, filamentous bacteria biology and pathogenicity. Burgess Publishing Co., Minneapolis.

40. Taptykova, S. D., and L. V. Kalakoutskii. 1973. Lowtemperature cytochrome spectra of anaerobic actinomycetes. Int. J. Syst. Bacteriol. 23:468-471.

41. Vega, L. E., and T. L. Gavan. 1970. Corynebacterium pyogenes - a pathogen in man. Report of a case. Cleveland Clin. Q. 37:207-214. 